\title{
Evaluating GPS Effectiveness for Natural Resource Professionals: Integrating Undergraduate Students in the Decision-Making Process
}

\author{
Daniel R. Unger, I-Kuai Hung, Yanli Zhang, \& David L. Kulhavy \\ Arthur Temple College of Forestry and Agriculture \\ Stephen F. Austin State University \\ Box 6109, SFA Station, Nacogdoches, TX 75962, USA
}

Received: Sep. 28, 2014 Accepted: Oct. 17, $2014 \quad$ Published: November 1, 2014

doi:10.5296/jse.v4i4.6389 URL: http://dx.doi.org/10.5296/jse.v4i4.6389

\begin{abstract}
Undergraduate students pursuing a Bachelor of Science in Forestry (BSF) degree at Stephen F. Austin State University (SFA) attend an intensive 6-week residential hands-on instruction in applied field methods. For students pursuing the BSF degree knowing the exact location of a forestland is crucial to the understanding and proper management of any related natural resource. The intensive 6-week instruction includes teaching how to use the Global Positioning System (GPS) to accurately record the spatial location of an earth's surface feature. After receiving hands-on instructions during the summer of 2014, students were taken to the field to collect real-world locations. Students compared two different GPS units within a forested setting and learned that the consumer-grade Garmin eTrex 30 was more precise than the Garmin eTrex Legend HCx. Overall objective was to validate the effectiveness of SFA's hands-on instructional methodology and to integrate undergraduate students in the decision making process of deciding which GPS unit a forester or natural resource manager should use to mark the spatial location of a natural resource. This study demonstrated that incorporating undergraduate students within a field-based research project preceded by hands-on instruction methodology enhances their undergraduate education and produces a more well-rounded society ready forester.
\end{abstract}

Keywords: Validation, Hands-on, Applied, Instruction, Natural resources 


\section{Introduction}

Undergraduate students pursuing a Bachelor of Science in Forestry (BSF) degree within the Arthur Temple College of Forestry and Agriculture (ATCOFA) at Stephen F. Austin State University (SFA), Nacogdoches, Texas, focus on the management of forests for wood products, wildlife habitat, recreational opportunities, and water quality. Major forces of change are guiding the direction of forestry including growth in human population, climate change, fundamental changes in the timber and fiber market and the explosion of invasive plants, pathogens and insects in the forest landscape (Wear and Greis, 2013). A forest manager must understand how plants and animals interact with their environment, possess a long-range view of a forest management plan, adapt to constantly changing economic conditions, and perceive the social interactions of people with the forest. Most importantly, a forest manager must recognize the forest as a dynamic entity that intimately links people, plants, and animals in a common community.

The mission of the BSF program within ATCOFA is to maintain excellence in teaching, research and outreach to enhance the health and vitality of the environment through sustainable management, conservation, and protection of our forests and natural resources. The program is accredited by the Society of American Foresters "to provide opportunities for students to acquire the knowledge, skills, abilities, and behaviors that clearly reflect employer, societal and environmental needs” (Layton, Allen, Belli, Bullard, Houghton, Rutherford, Selin, and Sharik, 2011; Society of American Foresters, 2011). The college is dedicated to comprehensive undergraduate and graduate education, basic and applied research programs, and service (Bullard, Coble, Coble, Darville, Rogers, and Stephens Williams, 2014). The goal in ATCOFA is to “produce foresters who are 'society ready,' i.e., capable of dealing effectively with the complex economic, ecological, and social issues involving forest resources today” (Bullard, Stephens Williams, Coble, Coble, Darville, and Rogers, 2014). In the ATCOFA educational program, students receive classroom and field-based experiences to prepare them for their professional careers. Academic courses provide learning opportunities that encourage and inspire students to approach forest resource, social and environmental issues in a critical yet creative manner, identify and analyze key elements, and articulate ethical solutions.

Students who decide to attend ATCOFA do so because they have chosen to pursue a career path based on three main items of concern where they can: make a difference, work outdoors, and use high end technology. To facilitate their career objectives undergraduate coursework within ATCOFA focuses on hands-on instruction, field exercises, and real-world applications using the most currently available geospatial technology (Unger, Kulhavy, Hung, and Zhang, 2014). All undergraduate students pursuing the BSF degree as part of their 130 credit requirement, who are majoring in forest management, wildlife, urban forestry, recreation or fire ecology, attend an off-campus residential 6-week hands-on intensive summer forestry field station for 6 credits.

Field station is composed of intensive hands-on instruction in applied field methods where the students learn practical applications that a multidisciplinary society ready forester needs 


\section{Macrothink}

to master to solve problems, issues, and concerns resource managers face on a daily basis. The 6-week hands-on instruction is broken down into weekly topics of field silviculture, timber cruising, wildlife, land measurement, harvesting and processing, and non-timber resources. Field station classes begin at 7:00 a.m. with field exercises until 5:00 p.m. followed by lecture and data analysis in the evening. Two faculty members rotate for each field station section for a total of 12 faculty members per summer. Since field station is a required component of each student's degree program an institutional review board is not required by SFA to attend field station.

The overall objectives of this research were to validate the effectiveness of ATCOFA's hands-on instructional methodology previously studied by the authors Unger, Kulhavy, Hung, and Zhang (2014) and to integrate undergraduate students in the decision making process of deciding which GPS unit a forester or natural resource manager should use to mark the spatial location of a natural resource. Although not unique to ATCOFA, as other forest schools have field stations similar to SFA's (Unger, Kulhavy, Hung, and Zhang, 2014), the integration of undergraduate students within a hands-on field station evaluation of geospatial technology within a southern forestry program is unique.

\section{Study Site}

The forestry field station is located at the Piney Woods Conservation Center (PWCC), a residential conservation center located adjacent to Angelina National Forest on the shores of Sam Rayburn Reservoir approximately 15 miles south of Broaddus, Texas (Figure 1). Constructed in 1985 for Stephen F. Austin State University's College of Forestry, the facility is used year round by the university, private and professional groups.

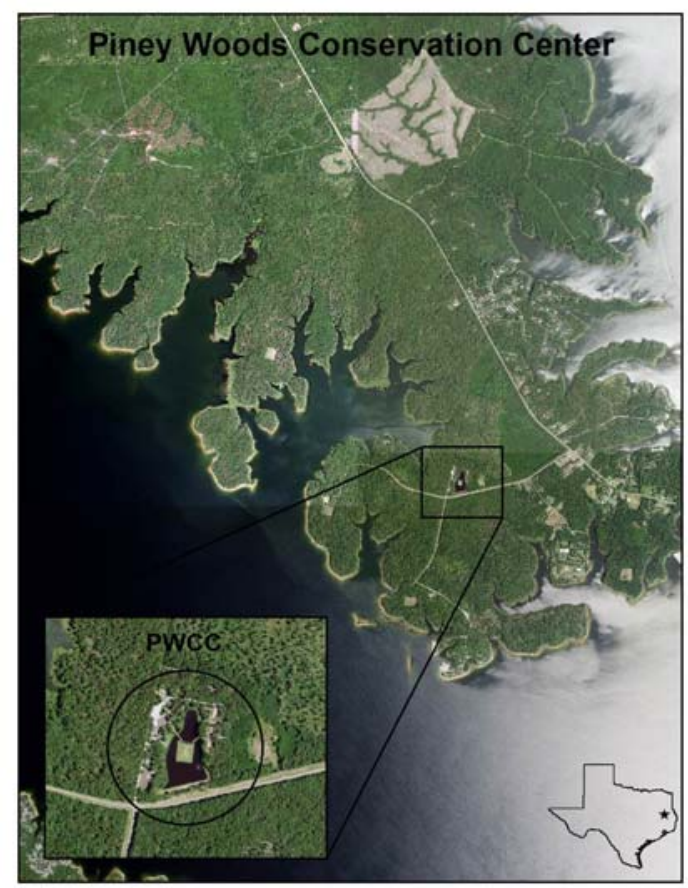

Figure 1. Location of the Piney Woods Conservation Center (PWCC) on the shores of Sam Rayburn Reservoir adjacent to the Angelina National Forest 
PWCC can accommodate 128 people with sleeping quarters arranged in suites. For field station, two students share a room and four share a connecting bathroom. Two dining rooms are located at the lodge area, one seats 150 people and the other 70, with high quality meals prepared and served from a modern kitchen. Four meeting rooms are available; two are centrally located within the dormitory buildings; one is located between the two dormitories; and one adjacent to the lodge. The meeting rooms can accommodate up to 150 people and are equipped with audio-video equipment. Faculty members also occupy a room at PWCC within close proximity to the students creating a student-faculty centered learning environment.

Instructors utilize the meeting room located between the two dormitories as a classroom for the entirety of field station. A typical day starts in the classroom at 7:00 a.m. followed by hand-on instruction and data collection in the adjacent Angelina National Forest and private forest lands. After returning to PWCC at the end of each day, typically at 5:00 p.m., students utilize a meeting room centrally located within one of the dorm buildings that is equipped as a computer lab to facilitate data analysis at the conclusion of each field day.

\section{Applied Spatial Science}

Spatial science, the study of spatial information describing the earth and its physical features, incorporates geographic information systems (GIS), GPS, remote sensing, surveying, and cartography. The rapid advancement of spatial technology, now part of our daily lives, includes personal GPS navigation devices and smart phones, professional GIS software (for business, public safety, oil and gas industry, natural resources, logistics and transportation, etc.), and web-GIS.

Embedded in 48 identified technical competencies required for producing society-ready foresters in ATCOFA was “Use Geospatial Technologies” which placed spatial science in the High Importance/High Performance quadrat of the 48 identified competencies required for a society-ready forester (Bullard, Stephen Williams, Coble, Coble, Darville, and Rogers, 2014). For students pursuing the BSF degree within ATCOFA knowing how to use GPS to derive the exact location of a forest or natural resource is crucial to its understanding and proper management. GPS is a satellite based navigation system that allows the user to identify the exact location of an object on the surface of the earth 24 hours a day in all weather conditions (Thurston, Poiker, and Moore, 2003). Surface objects are collected and categorized by their surface feature and represent either a point (e.g. bear den, field plot, etc...), line (e.g. stream, river, road, etc...), or polygon (e.g. lake, forest management unit, etc...) (Clarke, 2003; Heit and Shortreid, 1991; Lang, 1998). With the collection of a surface feature location via GPS technology the exact location, calculated length of a linear feature, or calculated area of a polygon feature can be extracted.

During the land measurement portion of field station students were trained on two consumer-grade GPS units, the Garmin eTrex Legend HCx and the Garmin eTrex 30 (Garmin International Inc., Olathe, KS), which are representative of the type of GPS units typically used by practicing natural resource managers within a forested environment. The use of a GPS unit in a forest environment presents many challenges (forest canopy blocks and degrades satellite signals and tree structure introduces multipath error) which the field station students are 
introduced to in the central classroom before collecting data in the field. Sigrist, Coppin, and Hermy (1999) found that canopy has a definite effect on horizontal and vertical positional accuracy and the relation appeared to be exponential; a small increase in canopy density resulted in a substantial increase in error. Yoshimura and Hasegawa $(2003,2006)$ found that horizontal positional accuracy and precision errors were highest in areas of dense canopy cover and lowest in areas of sparse canopy cover. Wing, Eklund, and Kellogg (2005) found that consumer-grade GPS receivers were accurate within 5 meters under open sky, 7 meters under young canopy, and within 10 meters under closed canopy in western Oregon. A study by Bolstad, Jenks, Berkin, Horne, and Reading (2005) confirmed those results with average errors of 6.5 and 7.1 meters under heavy forest canopy in Minnesota. In addition, a study by the authors Unger, Hung, Zhang, Parker, Kulhavy, and Coble (2013) determined that consumer-grade GPS units provide accurate spatial information for a practicing forester or natural resource manager and the accuracy of a derived spatial location was not related to the cost of the consumer-grade GPS units studied.

\section{Interactive Field-Based Instruction Methodology}

Validating the effectiveness of ATCOFA's hands-on instructional methodology previously studied by the authors Unger, Kulhavy, Hung, and Zhang (2014) by integrating undergraduate students in the decision making process of deciding which GPS unit a forester or natural resource manager should use was completed at field station during summer 2014. Prior to going in the field to collect real-world point data via the Garmin eTrex Legend HCx and Garmin eTrex 30 students were informed in the central classroom that they would be involved in a study designed to evaluate which GPS unit would be used in the future by forestry and natural resource professionals trained within ATCOFA (Figure 2). Students were also instructed how to enable their GPS units to ensure that their respective GPS units would collect data with real time correction via the Satellite Based Augmentation System (SBAS). The Garmin eTrex Legend HCx was enabled to collect data from the GPS constellation while the Garmin eTrex 30 was enabled to collect data from both the GPS and GLONASS constellation of satellites (Figures 3a-b). GLONASS stands for Global Orbiting Navigational Satellite System and it is the Russian counterpart to the U.S. GPS system. Students were informed that part of the study was to determine if adding the constellation of GLONASS satellites to their GPS receivers would increase the precision of their recorded spatial locations. 


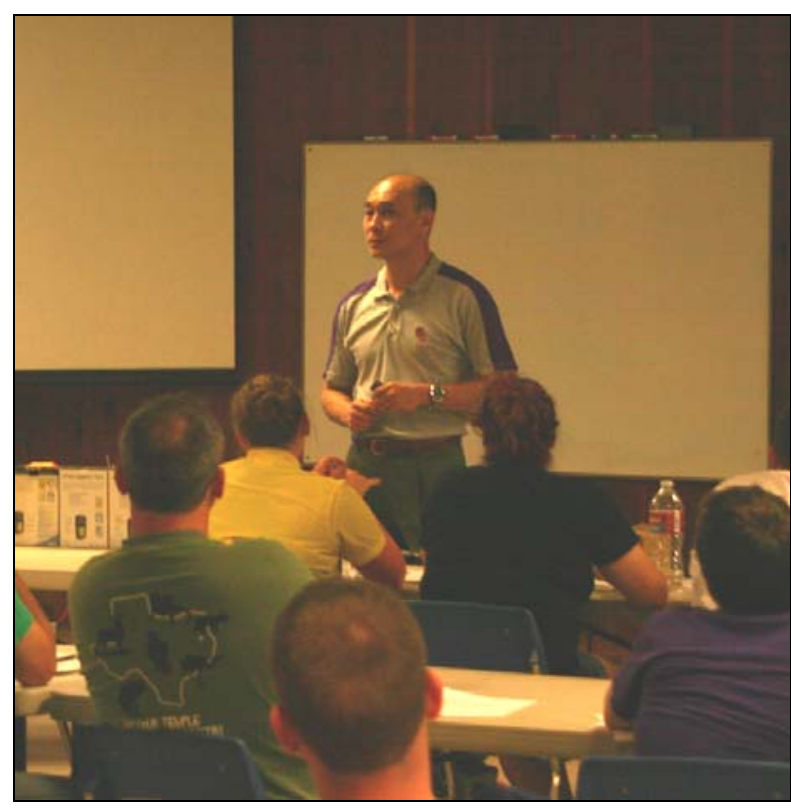

Figure 2. Informing students of their involvement in a GPS study in the central classroom

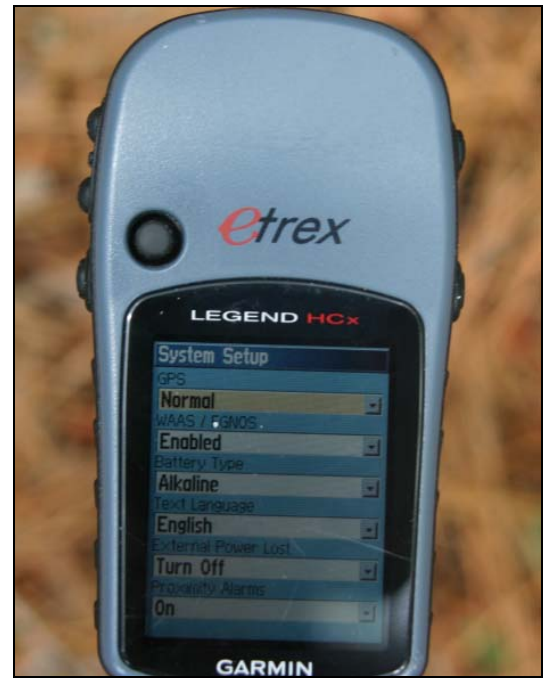

(a)

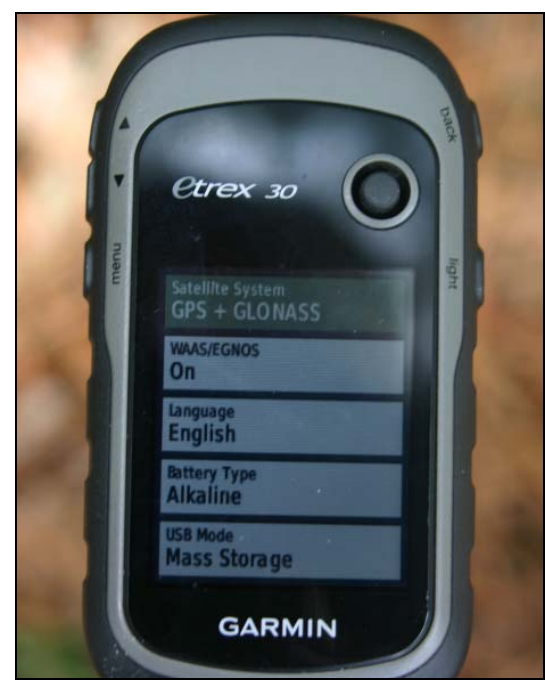

(b)

Figures 3a-b. Satellite data collection configuration for the Garmin eTrex Legend HCx (a) and the Garmin eTrex 30 (b)

SBAS is a collection of satellite systems that provide real time corrections data to GPS receivers to increase the accuracy of waypoints. The system in use in North America is the Wide

Area Augmentation System (WAAS) consisting of 38 ground reference stations in the U.S., Canada, and Mexico. The stations monitor GPS satellite data and transfer that data to three master stations which then upload correction messages (error) to multiple geosynchronous satellites. These satellites in turn distribute the correction message to GPS receivers that can apply the real time corrections in the field to increase waypoint accuracy thus increasing the 


\section{Macrothink}

Journal of Studies in Education

ISSN 2162-6952

2014, Vol. 4, No. 4

accuracy of any derived real-world unit (Arnold and Zandbergen, 2011; Federal Aviation Administration [FAA], 2010). Federal Aviation Administration specifications require that WAAS will provide 7.6 meter horizontal accuracy, a sizable improvement on the 10-15 meter accuracy that is usually specified for most consumer-grade GPS units gathering data autonomously (FAA, 2008). While helping the students prepare their GPS units for field data collection, the land measurement instructors also relayed to the students that a general term Global Navigation Satellite System (GNSS) is starting to become more widely used as it covers GPS (U.S. satellite system), GLONASS (Russian satellite system), Galileo (E.U. satellite system), and Beidou (Chinese satellite system).

Once the GPS units were configured to be WAAS enabled, the students were then taken to the island in the central portion of PWCC to receive one-on-one faculty instruction on how to collect an average waypoint (Figure 4). An average waypoint captures the GPS derived real-world coordinates representing the actual location of each GPS unit by taking the average of multiple waypoints recorded per spatial location to increase the accuracy of the recorded spatial location. Students were instructed via hands-on methodology how to record the average waypoint per GPS unit: for the Gamin eTrex Legend HCx it was the average of 30 individual positions while for the Garmin eTrex 30 it was the resultant average waypoint recorded when the Garmin eTrex 30 GPS unit sample confidence level reached 100 percent (Figures 5a-b). Students were also instructed how to collect their waypoint location data in the Universal Transverse Mercator (UTM) coordinate system, the typical coordinate system required by most natural resource based entities.

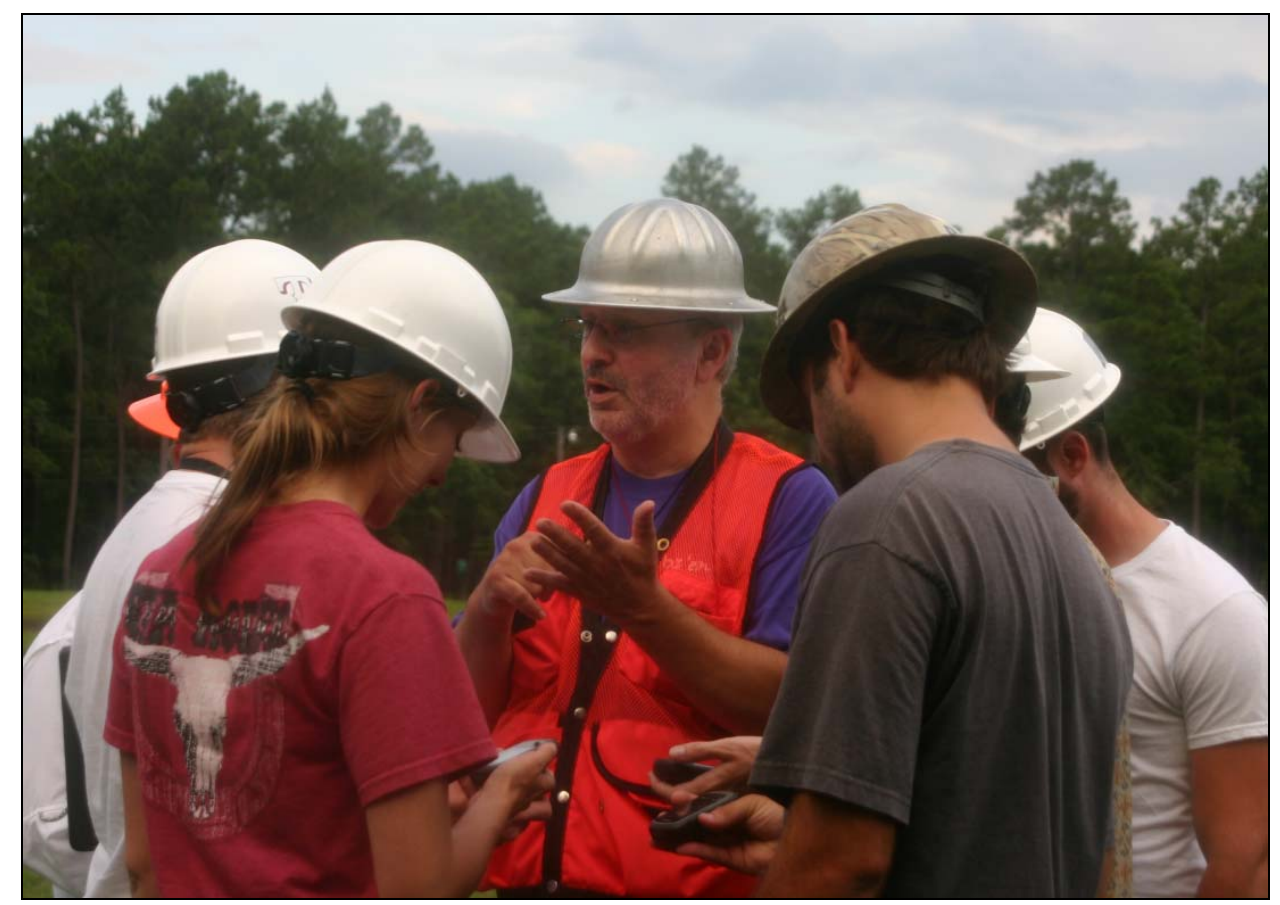

Figure 4. Interactive faculty GPS instruction on the island prior to going to the field 


\section{Macrothink}

Journal of Studies in Education ISSN 2162-6952

2014, Vol. 4, No. 4

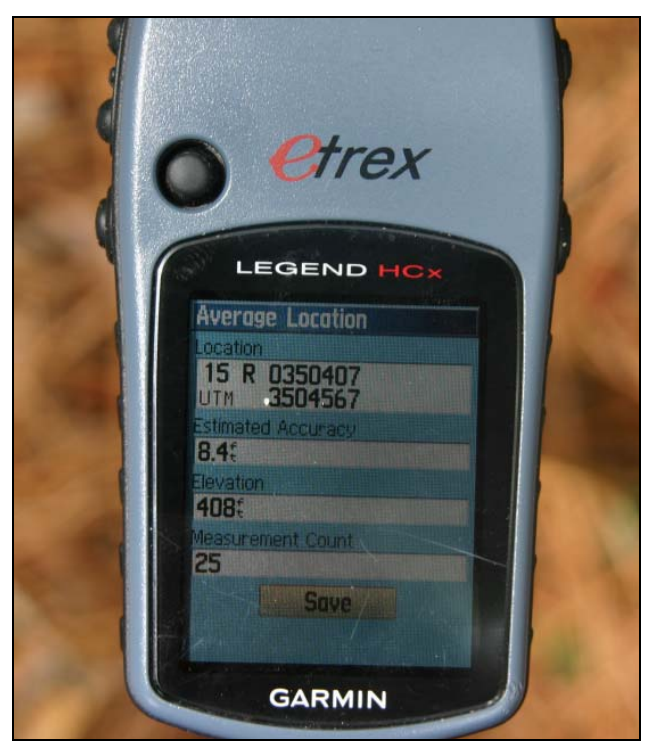

(a)

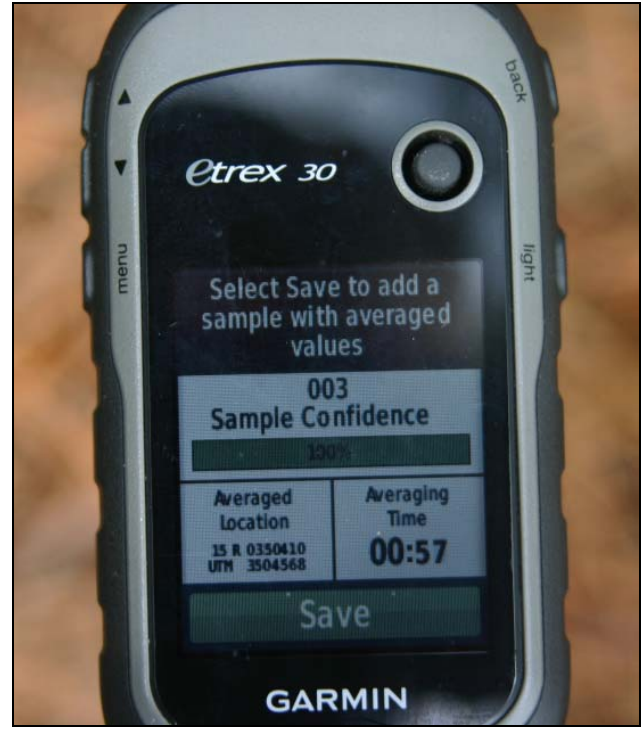

(b)

Figures 5a-b. Average waypoint interface for the Garmin eTrex Legend HCx (a) and the Garmin eTrex 30 (b)

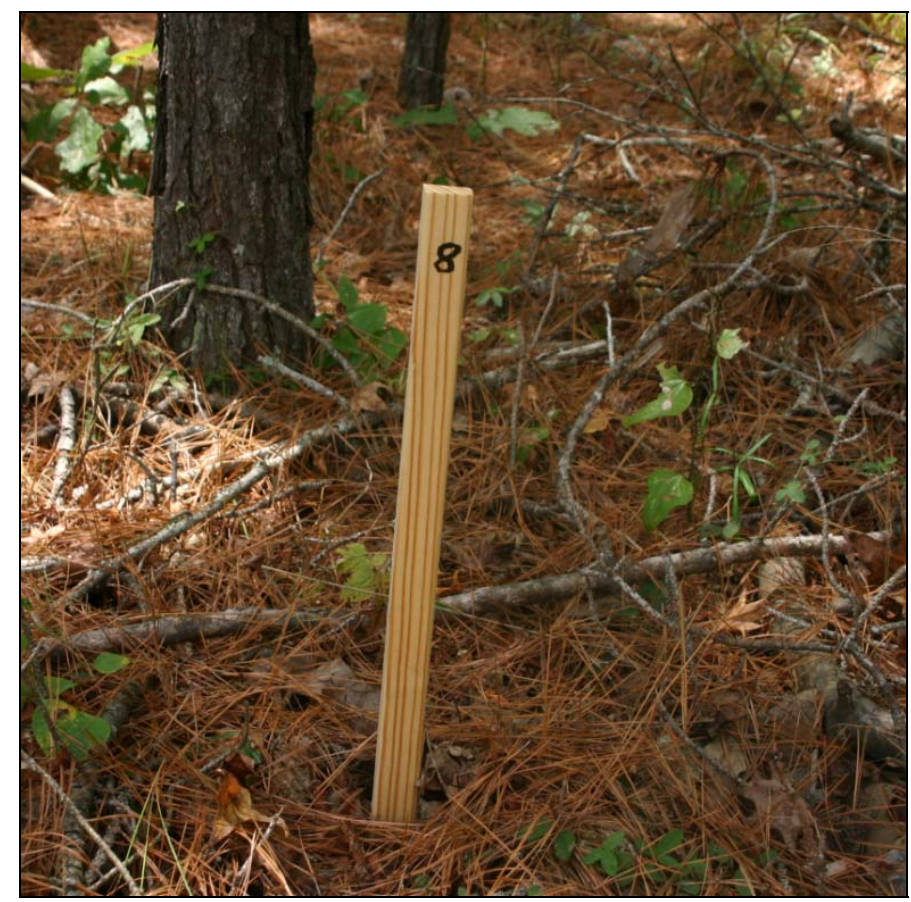

Figure 6. Wooden stake identifying faculty chosen waypoint location number eight 


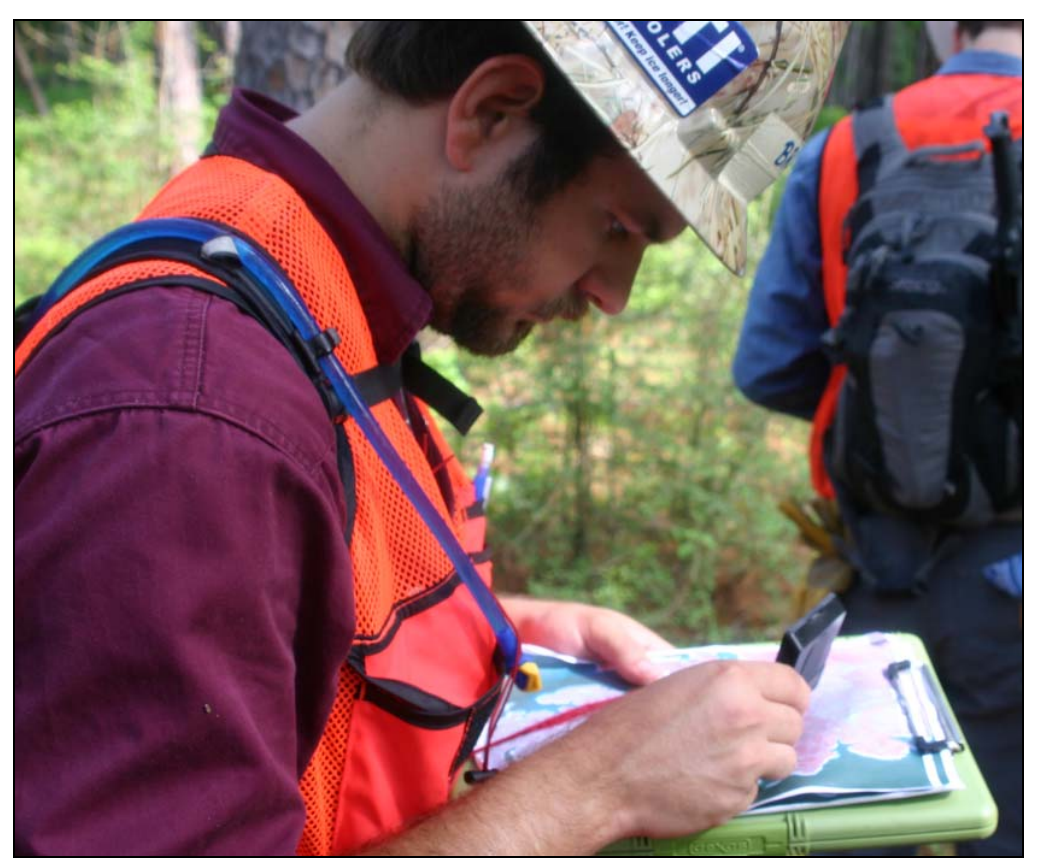

Figure 7. Students navigating to each faculty chosen location with a map and compass

Once the initial hands-on instruction on the island was completed, students were taken to the field to collect the average waypoint of 11 faculty chosen spatial locations within the adjacent Angelina National Forest that were identified with a labelled stake (Figure 6). The students navigated to each identified waypoint in the field using compass and pacing (Figure 7) and collected the average waypoint for each of the 11 locations using the Garmin eTrex Legend HCx and the Garmin eTrex 30 GPS units while placing each GPS unit directly above each stakes location (Figure 8). In the field the students collected data independently to increase confidence and to validate their GPS knowledge. Faculty members travelled with the students to provide further instruction as needed.

\section{Interactive GIS Lab Results}

After all average waypoint locations in the field were recorded, the students returned to PWCC and used the meeting room that is transformed and equipped as an interactive computer lab for data analysis. The students then received one-on-one faculty instruction on how to transfer the collected average waypoints within the Garmin eTrex Legend HCx and Garmin eTrex 30 to ArcMap 10.1 (Environmental Systems Research Institute, Redlands, CA) using DNRGPS (Department of Natural Resources, State of Minnesota) software to communicate between each GPS unit and a desktop PC (Figure 9). ArcMap 10.1 was utilized to produce high quality map products portraying the spatial location of each collected average waypoint for inclusion in their daily report. 


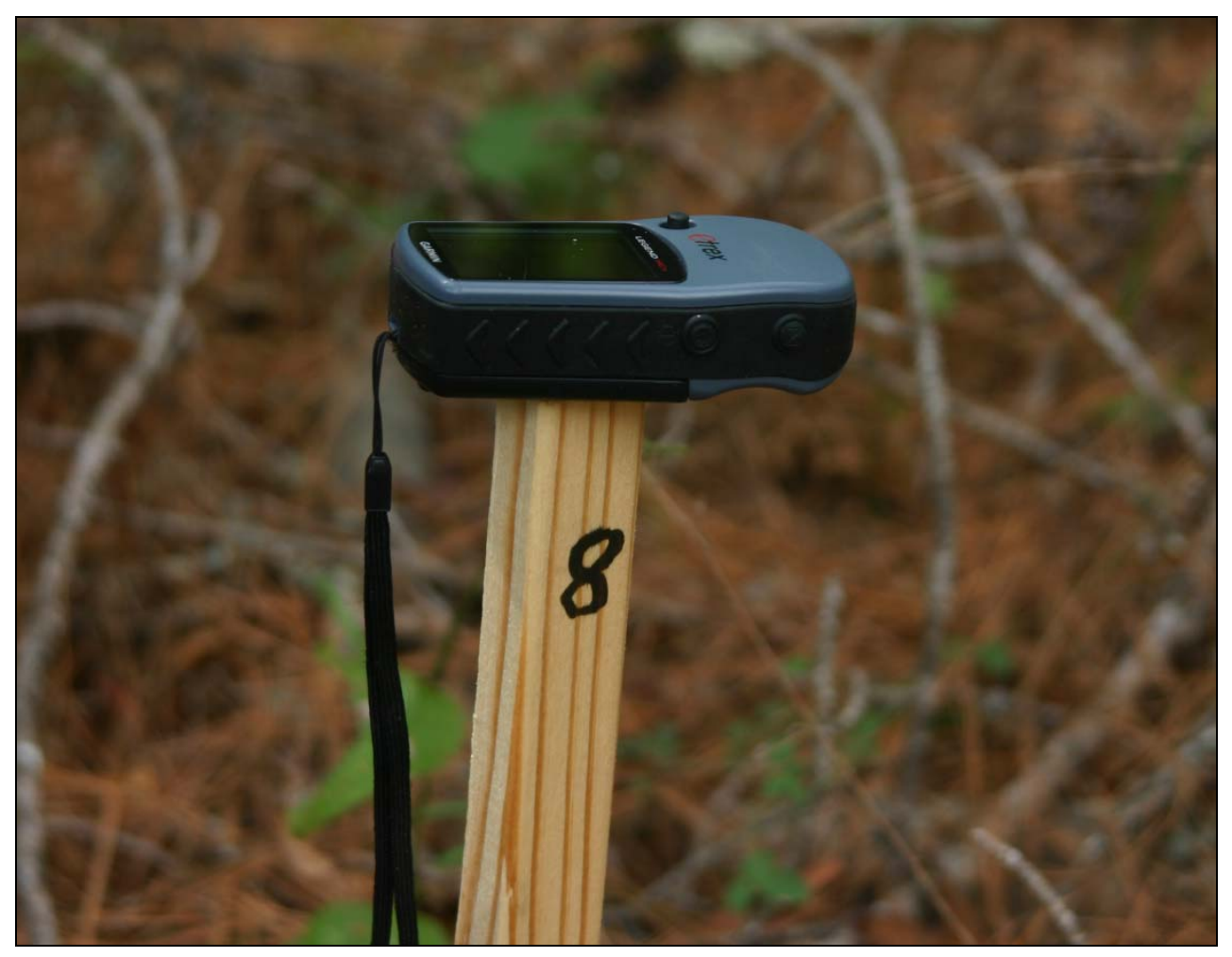

Figure 8. Placing a GPS unit above a wooden stake to collect the average waypoint for location number eight

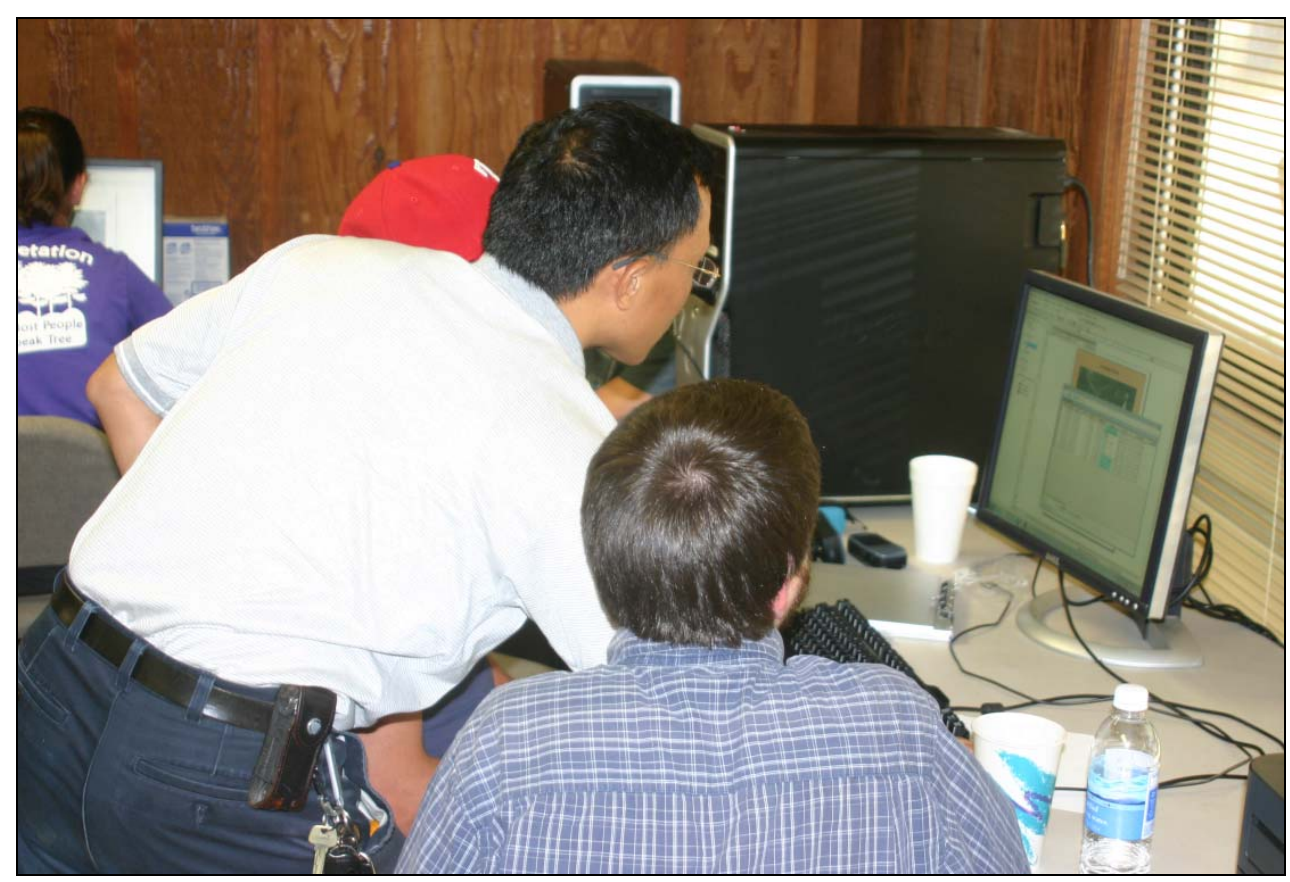

Figure 9. Interactive faculty instruction showing students how to download their GPS data to a PC after returning from the field

A visual assessment of student collected average waypoints at all 11 identified locations, which was displayed on screen to all the students in the central classroom to validate their 


\section{Macrothink}

data collection and GPS unit comparison analysis, indicated that the Garmin eTrex 30 was more precise than the Garmin eTrex Legend HCx (Figure 10). In order to compare the precision of the Garmin eTrex Legend HCx and the Garmin eTrex 30 quantitatively, the standard distance $(d)$ was calculated for each of the 11 waypoint locations and for each GPS model used (Equation 1).

$$
d=\sqrt{\frac{\sum_{i=1}^{n}\left(x_{i}-\mu_{x}\right)^{2}+\left(y_{i}-\mu_{y}\right)^{2}}{n}} \quad \text { Eq. } 1
$$

The variable $n$ represents the total number of positions collected by each GPS model. For our case $n$ equals 11, representing 11 positions recorded by 11 GPS units of the same model. Variables $x_{i}$ and $y_{i}$ are the UTM coordinates of each recorded position and $\mu_{x}$ and $\mu_{y}$ is the mean center of all the UTM coordinates collected for each waypoint with the same GPS model.

A mean center $(\bar{S})$ is calculated by using Equation 2.

$$
\bar{S}=\left(\mu_{x}, \mu_{y}\right)=\left(\frac{\sum_{i=1}^{n} x_{i}}{n}, \frac{\sum_{i=1}^{n} y_{i}}{n}\right) \quad \text { Eq. } 2
$$

The area of a standard deviational ellipse was also calculated for each cluster of waypoint GPS positions by using Equation 3, where the standard distances for $\mathrm{x}$ coordinates and for $\mathrm{y}$ coordinates are calculated separately. Then an ellipse was plotted for each waypoint that is rotated to an angle for the long and short axes of the ellipse displaying a trend of the spatial distribution of coordinates for a waypoint for the two GPS models analyzed.

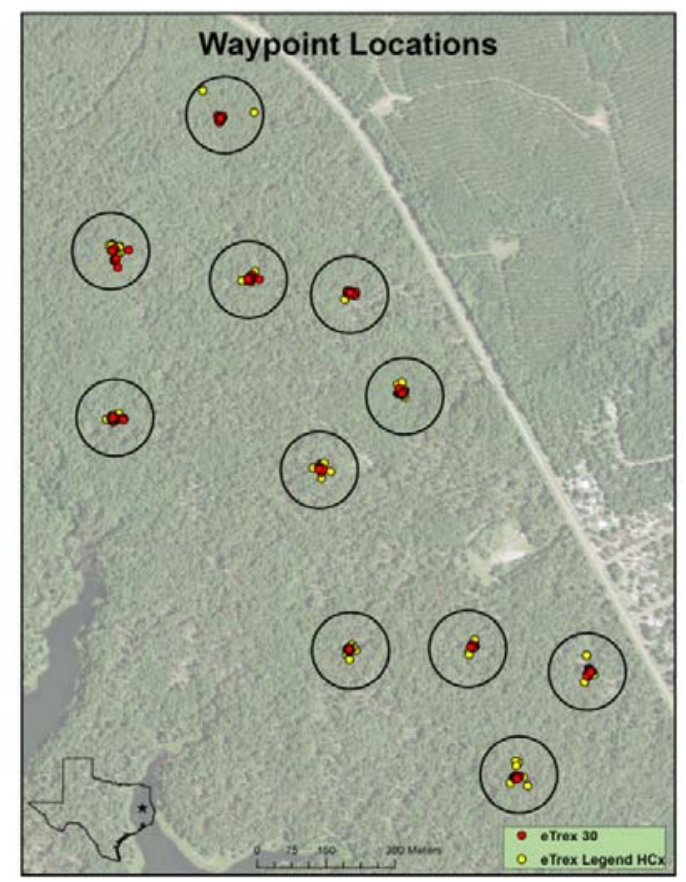

Figure 10. Visual assessment shown to the students showing the difference between their Garmin eTrex Legend HCx and the Garmin eTrex 30 average waypoints 


$$
d_{x}=\sqrt{\frac{\sum_{i=1}^{n}\left(x_{i}-\mu_{x}\right)^{2}}{n}}, d_{y}=\sqrt{\frac{\sum_{i=1}^{n}\left(y_{i}-\mu_{y}\right)^{2}}{n}} \text { Eq. } 3
$$

Both standard distance and directional ellipse area are indicators of precision. A lower value represents a more clustered group of points that indicates a higher level of precision in identifying a spatial location. Results as shown in Table 1 indicate the Garmin eTrex 30, with a lower average standard distance $(6.3 \mathrm{~m})$ and lower average ellipse area (140.3 sq $\mathrm{m}$ ), had a higher level of precision than the Garmin eTrex Legend HCx. A paired $t$-test confirmed the difference on positional precision between the two GPS models tested which was statistically significant ( $P=0.01$ for standard distance and $P=0.04$ for ellipse area) at the 95\% confidence interval (Table 2).

When plotting the cluster of GPS coordinates for each waypoint by GPS model tested, it is was clear that the positions of the Garmin eTrex Legend HCx were more dispersed than those of the Garmin eTrex 30 (Figure 11). The superimposed summary circle (based on mean center and standard distance) and directional ellipse help in detailed visualization of waypoint locations where each GPS model achieved its highest and lowest precision. Providing the students with read-world quantitative information helped to relay to the students the results from their GPS precision comparison and to enforce the importance of involving undergraduate students in the decision-making process as an addendum to their educational experience.

Table 1. Summary of standard distance and ellipse area for each group of waypoint positions by GPS model

\begin{tabular}{lllll}
\hline ID & \multicolumn{2}{l}{ Standard Distance (m) } & \multicolumn{2}{l}{ Ellipse Area (sq m) } \\
\hline \multirow{2}{*}{ Legend } & 30 & Legend & 30 \\
\cline { 2 - 5 } 2 & 19.9 & 3.8 & 1033.5 & 41.7 \\
3 & 10.2 & 2.8 & 302.2 & 23.1 \\
4 & 12.1 & 4.1 & 456.4 & 45.4 \\
5 & 12 & 9 & 311.3 & 152.8 \\
6 & 12.8 & 16.5 & 483.5 & 800.3 \\
7 & 30.9 & 5.5 & 2726.8 & 94.8 \\
8 & 7.7 & 5.6 & 178.3 & 69.4 \\
9 & 10.3 & 5.3 & 285.5 & 81.8 \\
10 & 9.4 & 3.5 & 90.2 & 32.6 \\
11 & 14.6 & 5.2 & 412.4 & 57.9 \\
\hline Average & $\mathbf{1 3 . 6}$ & $\mathbf{6 . 3}$ & $\mathbf{5 8 9 . 8}$ & $\mathbf{1 4 0 . 3}$ \\
\hline
\end{tabular}




\section{Macrothink}

Journal of Studies in Education

ISSN 2162-6952

2014, Vol. 4, No. 4

Table 2. Summary of $t$-test with paired two samples for mean of standard distance and ellipse area

\begin{tabular}{lllll}
\hline & \multicolumn{2}{l}{ Standard Distance $(\mathrm{m})$} & \multicolumn{2}{l}{ Ellipse Area (sq m) } \\
\hline \multirow{2}{*}{ Mean } & Legend & 30 & Legend & 30 \\
\cline { 2 - 5 } Variance & 13.6 & 6.3 & 589.8 & 140.3 \\
Observations & 44 & 14.7 & 564221.2 & 49709.6 \\
$\mathrm{df}$ & 11 & 11 & 11 & 11 \\
$t$ Value & 10 & & 10 & \\
$P$-Value & 3.09 & & 1.89 & \\
t Critical one-tail & 1.81 & & $\mathbf{0 . 0 4}$ & \\
\hline
\end{tabular}

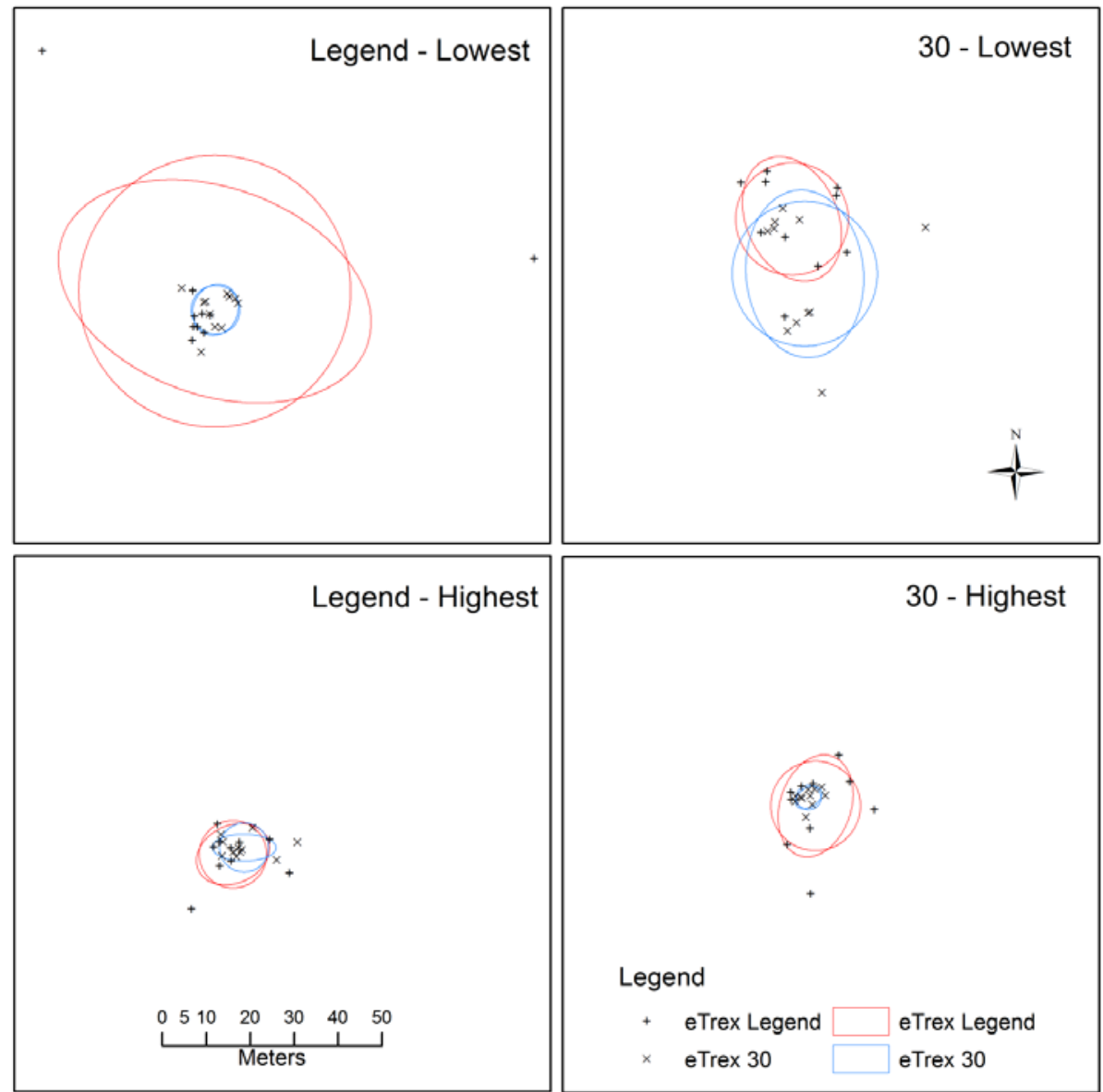

Figure 11. Cluster plot of the Garmin eTrex Legend HCx and the Garmin eTrex 30 waypoints. 


\section{Student Learning Outcomes}

ATCOFA is known for its teaching philosophy: make a difference, work outdoors, and use high end technology to solve problems, issues, and concerns foresters and natural resource managers face on a daily basis. To achieve that objective undergraduate coursework within ATCOFA focuses on hands-on instruction, field exercises, and real-world applications within the field station portion of their curriculum. Since accurate quantitative data are crucial in any forest or natural resource management plan, a student being able to accurately assess real-world location data is essential. Within the land measurement portion of field station students learned via one-on-one faculty instruction how to use two different consumer-grade GPS units to collect average waypoints within a forest setting. By comparing two different GPS units within a forested setting students learned that the consumer-grade Garmin eTrex 30 was more precise than the Garmin eTrex Legend HCx which validates previous work by the authors (Unger, Hung, Zhang, Parker, Kulhavy, and Coble, 2013). The higher level of precision obtained by the Garmin eTrex 30 also validates the hands-on methodology applied in the field by the ATCOFA faculty (Unger, Kulhavy, Hung, and Zhang, 2014). Overall, this study demonstrated that incorporating undergraduate students within a field-based research project preceded by hands-on instruction methodology enhances their undergraduate education and helps produce a more well-rounded society ready forester.

\section{References}

Arnold, L., \& Zandbergen, P. (2011). Positional accuracy of the Wide Area Augmentation System in consumer-grade GPS units. Computers \& Geoscience, 37, 883-892. http://dx.doi.org/10.1016/j.cageo.2010.12.011

Bolstad, P., Jenks, A., Berkin, J., Horne, K. \& Reading, W. H. (2005). A comparison of autonomous, WAAS, real-time, and post-processed global positioning systems (GPS) accuracies in northern forests. Northern Journal of Applied Forestry, 22, 5-11.

Bullard, S., Coble, D., Coble, T., Darville, R., \& Stephen Williams, P. (2014). Producing 'Society-ready' Foresters: A research-based process to revise the Bachelor of Science in Forestry Curriculum at Stephen F. Austin State University. Arthur Temple College of Forestry and Agriculture, Stephen F. Austin State University, Nacogdoches, Texas, ATCOFA Monograph 1-2014.

Bullard, S., Stephens Williams, P., Coble, T., Coble, D., Darville, R., \& Rogers, L. (2014). Producing "Society-ready" Foresters: A research-based process to revise the Bachelor of Science in Forestry Curriculum at Stephen F. Austin State University. Journal of Forestry, 112, 354-360. http://dx.doi.org/10.5849/jof.13-098

Clarke, K. (2003). Getting started with geographic information systems. Upper Saddle River, New Jersey: Prentice Hall.

FAA. (2008). Wide-area augmentation system performance analysis report. Federal Aviation Administration, William J. Hughes Technical Center, NSTB/WAAS T\&E Team Report No. 24. 
FAA. (2010). WAAS: Quick facts, 2010. Federal Aviation Administration. Retrieved from http://www.faa.gov/about/office_org/headquarters_offices/ato/service_units/techops/navservi ces/gnss/waas/

Heit, L., \& Shortreid, A. (1991). GIS applications in natural resources. Loveland, Colorado: J. L. Printing.

Lang, L. (1998). Managing natural resources with GIS. Redlands, California: ESRI.

Layton, P., Allen, J., Belli, K., Bullard, S., Houghton, J., Rutheford, A., ... Sharik, T. (2011). National association of university forest resources programs undergraduate educational enhancement strategy. National Association of University Forest Resources Programs, Washington, D.C.

Sigrist, P., Coppin, M., \& Hermy, M. (1999). Impact of forest canopy on quality and accuracy of GPS measurements. International Journal of Remote Sensing, 20, 3595-3610. http://dx.doi.org/10.1080/014311699211228

Society of American Foresters. (2011). Accreditation handbook: standards, procedures, and guidelines for accrediting educational programs in professional forestry. Bethesda, Maryland: Society of American Foresters.

Thurston, J., Poiker, T., \& Moore, J. (2003). Integrated spatial technologies. New Jersey: John Wiley \& Sons.

Unger, D., Hung, I., Zhang, Y., Parker, J., Kulhavy, D., \& Coble, D. (2013). Accuracy assessment of perimeter and area calculations using consumer-grade global positioning system (GPS) units in southern forests. Southern Journal of Applied Forestry, 37, 208-215. http://dx.doi.org/10.5849/sjaf.13-006

Unger, D., Kulhavy, D., Hung, I., \& Zhang, Y. (2014). Quantifying natural resources using field-based instruction and hands-on applications. Journal of Studies in Education, 4, 1-14. http://dx.doi.org/10.5296/jse.v4i2.5309

Wear, D., \& Greis, J. (2013). The southern forest futures project: technical report. USDA Forest Service General Technical Report, Southern Research Station, Asheville, North Carolina, Report SRS- 178.

Wing, M., Eklund, A., \& Kellogg, L. (2005). Consumer-grade global positioning system (GPS) accuracy and reliability. Journal of Forestry, 103, 169-173.

Yoshimura, T., \& Hasegawa, H. (2003). Comparing the precision and accuracy of GPS positioning in forested areas. Journal of Forest Research, 8, 147-152. http://dx.doi.org/10.1007/s10310-002-0020-0

Yoshimura, T., \& Hasegawa, H. (2006). High-end GPS vs. low-end GPS: comparing GPS positioning accuracy in the forest environment. In UFRO Precision Forestry Symposium, Stellenbosch, South Africa, p. 429-436. 